\title{
Clinical-epidemiological and pharmacoepidemiological investigation of acute cerebrovascular accidents
}

\author{
Oksana R. Levytska ${ }^{1 *}$, Bohdan P. Hromovyk ${ }^{1}$, Liana M. Unhurian ${ }^{2}$, Kateryna V. Kostyana ${ }^{2}$ \\ ${ }^{1}$ Department of Organization and Economics of Pharmacy and ${ }^{3}$ Department of Clinical Pharmacy, Pharmacotherapy and Medical Standardization, Danylo \\ Halytsky Lviv National Medical University, Lviv, Ukraine. ${ }^{2}$ Department of Organization and Economics of Pharmacy, Odessa National Medical \\ University, Odessa, Ukraine.
}

\section{ARTICLE INFO}

Article history:

Received on: 08/02/2017

Accepted on: 17/05/2017

Available online: 30/07/2017

Key words:

Acute cerebrovascular accidents, drug prescribing, treatment, drug consumption.

\begin{abstract}
Acute cerebrovascular accidents belong to leading causes of disability and death worldwide, in Ukraine in particular. Hence, proper medical-and-pharmaceutical aid is crucial for the positive outcomes. Our clinicalepidemiological analysis of inpatient medical records showed that ACVA occurred in $77.6 \%$ of male and $76.0 \%$ of female patients aged 50 and over. Cerebral infarction was diagnosed in $50.3 \%$ of patients, $44.3 \%$ - sequelae of cerebrovascular disease, and $8.7 \%$ - cerebral hemorrhage. Hypertension was the prevalent concomitant disorder, with the rate of $82.0 \%$ of cases. The content-, frequency-, ABC, ATC/DDD, DU $90 \%$ analyses, and generalization allowed establish the trends, amounts and structure of drug consumption. Among 198 of drugs, the max specific weight belonged to those effecting on cardiovascular system (29.8\%). We identified 8 most frequently prescribed drugs. High rates of consumption were typical for 3 drugs. The $90 \%$ of consumed DDDs accounted for 45 drugs. Atorvastatin, Dexamethasone, and Enoxaparin were characterized by high numbers of DDDs per 100 bed-days. Consumption of antihypertensive, anticoagulant and antiplatelet agents intended for basic and specific therapy, and secondary prevention of ACVA, equaled $58.0 \%$ of the total DDDs' number. Results of the research may act as a background for rational drug prescribing for patients with ACVA.
\end{abstract}

\section{INTRODUCTION}

Acute cerebrovascular accidents (ACVA) and stroke as the most severe manifestation of those have been an important medical and social problem worldwide for many years. Thus, according to the medical statistics data, in 2014 acute stroke, ischemic heart disease and lower respiratory tract infections have been the main reasons for lost years of life due to premature death (WHO, 2014). In Ukraine, the rates of morbidity and mortality from stroke stay consistently high and overweigh those

* Corresponding Author

Phone : +380931027557, +380976759269

Email: levytska.oksana@gmail.com of the majority of European countries (Revenko, 2010; Filipets, 2014). That is why providing adequate medical care of patients with ACVA is extremely important. All the stages of such medical aid are strongly interconnected with pharmaceutical aid. The basis of a high-quality pharmaceutical (hence - medical) aid is the application of clinically and economically effective drugs, namely rational drug application (WHO, 1996). In its turn, rational drug use is considered one of the appropriate pharmacotherapeutic practice and polypragmasy prevention principals (Ministry of Health of Ukraine, 2013). It can be achieved through drug consumption analysis, carried out worldwide (Smuseva et al., 2012; Basavaraju and Panchaksharimath, 2016; Hanssens et al., 2002; Volodina et al., 2011; Sharonjeet Kaur et al., 2014; Sagar et al., 2015) and in Ukraine (Kotvitska and Lobova, 2015; Levytska and Hromovyk, 2012; Mishchenko and Adonkina, 2015; Yakovleva and Ribka, 2013). 


\section{MATERIALS AND METHODS}

\section{Objects of the research}

We analyzed inpatient medical records and prescription papers $(n=2358)$ of patients of the neurological department based at one of inpatient hospitals in Lviv. Lviv Regional Clinical Hospital is a general hospital that provides high-quality medical aid for population of Lviv region, other regions of Ukraine and foreigners. The Bed capacity of the hospital equals 1110 and embraces 27 inpatient hospital departments, including neurological department for 75 beds. The study was held in 2015, hospital permission from 10th April 2015 in Minutes No 1062/07.

\section{Type of the research}

Our research had retrospective character.

Clinical-epidemiological study was directed on identifying different types of ACVA, their gender and age specifics, range of comorbidities, duration of hospitalization.

Pharmaco-epidemiological study itself was identifying drugs for pharmacological treatment of defined ACVA types and correlation of its duration, sequence with age, types and number of comorbidities.

\section{The methods used in the research}

Content analysis consisted in identifying the International Nonproprietary Name (INN) for each drug or accredited name (AN) in case of no INN and ranging them according to the levels of Anatomical Therapeutic Chemical (ATC) Classification System, defining specific weight for each group on different levels.

Retrospective frequency analysis was provided in two directions: we identified both the share of patients who had been prescribed some certain drug and the share of certain drug in the total amount of prescriptions (structure of prescriptions). The drugs were classified in range from the most to the least prescribed ones. For this purpose, we selected inpatient prescription papers (IPPs) in chronological order of patients being hospitalized. We formed the sample of medications as for INN or AN, and indicated the calculated number of prescriptions for each drug from each IPP. Then the drugs were placed in order of decline from the most to the least prescribed ones. The share of each drug in the total structure of prescriptions and the share of patients for whom the certain drugs had been prescribed were calculated. The results of the frequency analysis were represented as a proportion of patients who were prescribed the drug or as a share of drug in the total amount of all prescriptions.

Using $\mathrm{ABC}$ analysis (Pareto principle, 80/20 rule), we divided medications from the sample into 3 categories $(\mathrm{A}, \mathrm{B}$, and C) according to frequency of prescriptions (hence - their estimated importance of being prescribed) for patients with ACVA. The "A" group includes $10-20 \%$ of the total, prescribed in $70-80 \%$ of cases. Group "B" includes $20-30 \%$ of drugs that were prescribed in 15 $20 \%$ of cases. The rest form group " $\mathrm{C}$ ".
The rates of consumption were calculated with the help of ATC/DDD and drug utilization (DU) $90 \%$ analyses. The defined daily dose (DDD) - the average maintenance dose of the drug when used on its major indication in adults (WHO, 2003) was calculated. We took the information about the amount of consumed drug (tabs, capsules, vails etc.) from the inpatient prescription paper. Considering the amount of the active ingredient in the defined dosage forms, we counted the total amount of the drug in grams, milligrams, units etc. Afterwards we calculated the number of consumed DDDs as the ratio of the total amount of consumed drug (mg, g etc.) to the value of DDD. Findings were rated from the max number of consumed DDDs to min number of those. In addition, the consumption indicator showing a number of DDDs per 100 bed-days was set. The calculations were performed using the formula as follows: DDDs/100 bed-days $=($ DDDs $x 100)$ / total number of bed-days. The DU $90 \%$ analysis showed number of drugs that owned $90 \%$ of consumed DDDs. Each prescribed drug was ranged from max to min value of DDD. The share of each drug in the total amount was defined. The total number of drugs was taken for $100 \%$. We formed two groups of drugs. The first included drugs that make $90 \%$ of all consumed DDDs. The rest of the drugs were included into the second group. Generalization of results helped to make the conclusions.

The conflict of the interests in the course of the research was not reported. The Conclusion of Human Research Ethics Committee of Danylo Halytsky Lviv National Medical University is in Minutes No 4, 20th April 2015.

\section{Statistics}

Statistical data processing was performed with the help of Statistica 10 Trial software (StatSoft, 2010). The quantitative measures (age, number of comorbidities, and duration of treatment) were compared. For the processed indicators the average value was identified and standard deviation (SD) specified. Normality of data distribution in samples was evaluated by means of Shapiro-Wilk test. Whereas the data distribution differs from the normal, the non-parameter methods were used for their evaluation, the Kolmogorov-Smirnov test in particular. Differences were considered significant when $\mathrm{p}<0.05$ (Serhiienko, 2000).

\section{RESULTS AND DISCUSSION}

In the analyzed period, 2358 patients had been treated at the neurological department, 300 of them (12.7\% of the total) with ACVA. There were 183 male and 117 female patients (correlation 1.6: 1). Age range for male patients was within $18-96$ years, the average age $(\mathrm{m} \pm \mathrm{SD})$ was $58.2 \pm 13.79$ years (median score of 57 years, $25 \%-51$ year, $75 \%$ - 68 years). For women the age range was within $18-87$ years, and the average age was $62.9 \pm 15.48$ years (median score of 66 years, $25 \%-50$ years, $75 \%-76$ years) ( $\mathrm{p}<0.001)$. Therefore, differences due to age between men and women were significant (fig.1). The frequency of ACVA in 
patients of the neurological department, standardized by age and gender is represented on fig. 2 .

According to the data represented on the fig. 2 , in both groups ACVA as usual developed in the age of 50 and elder (total $77.6 \%$ of cases in men and $76.0 \%$ of cases in women). Therewith, ACVA in male patients aged 55 - 59 years was marked 5 times more often than in female patients of the same age. Starting from the age of 65 years, the trend changed to the opposite: the number of ACVA cases was almost twice higher in women. Women in the age of 80 and elder 2.6 times more often suffered from ACVA. Some $50.3 \%$ of patients were diagnosed cerebral infarction (names of vascular brain disorders are represented according to the
International Statistical Classification of Diseases and Related Health Problems 10th Revision (WHO, 2015)), 44.3\% - sequelae of cerebrovascular disease, in $8.7 \%$ - hemorrhage (intracerebral, subarachnoid etc.). As in some inpatient medical records not 1 but 2 diagnoses were indicated, the total amount of cerebrovascular disorders equals somewhat higher than $100 \%$. Correlation of ischemic strokes to cerebral hemorrhage was 5.8:1, namely, ischemic strokes occurred 5.8 times more often than hemorrhage. Monitoring of comorbidities in patients with ACVA showed those were diagnosed in $96.2 \%$ of males and in $97.4 \%$ of females. Min amount of comorbidities in male patients equaled 1 , max -12 , the average amount of comorbidities was $4.3 \pm 2.26$ (median score of 4 disorders, $25 \%-3$ disorders, $75 \%-6$ disorders) (fig. 3 ).

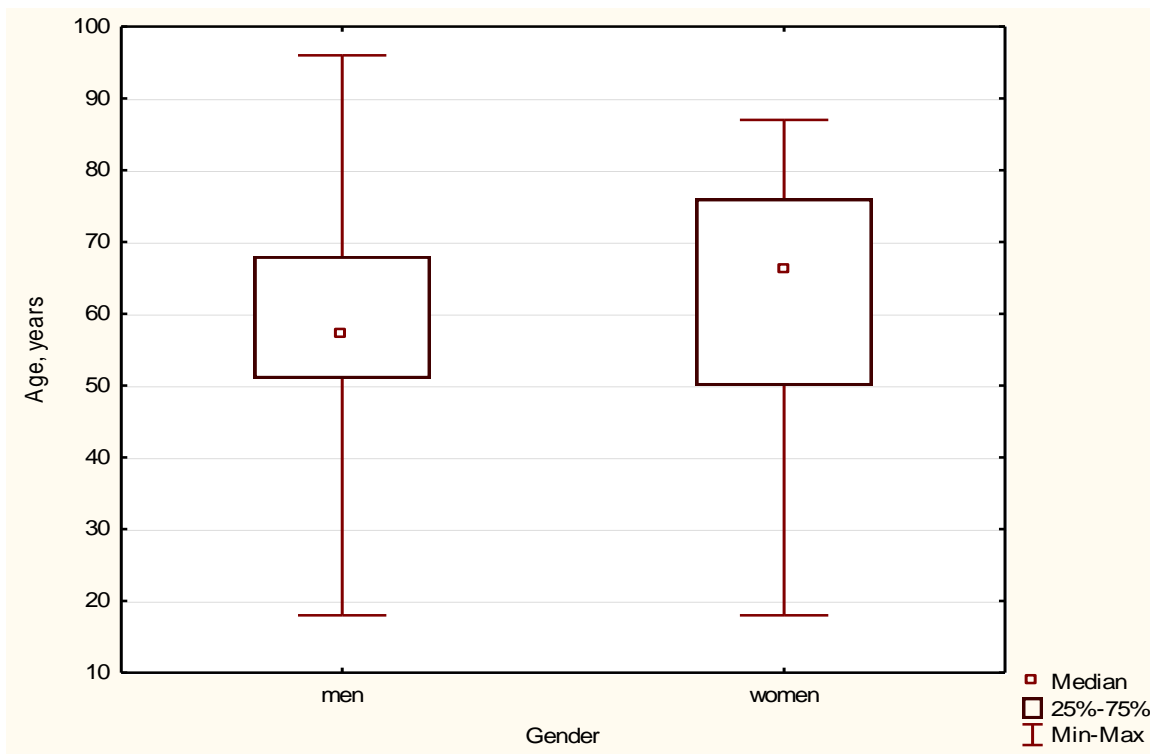

Fig. 1: "Box-and-whisker" plot for patients' gender and age.

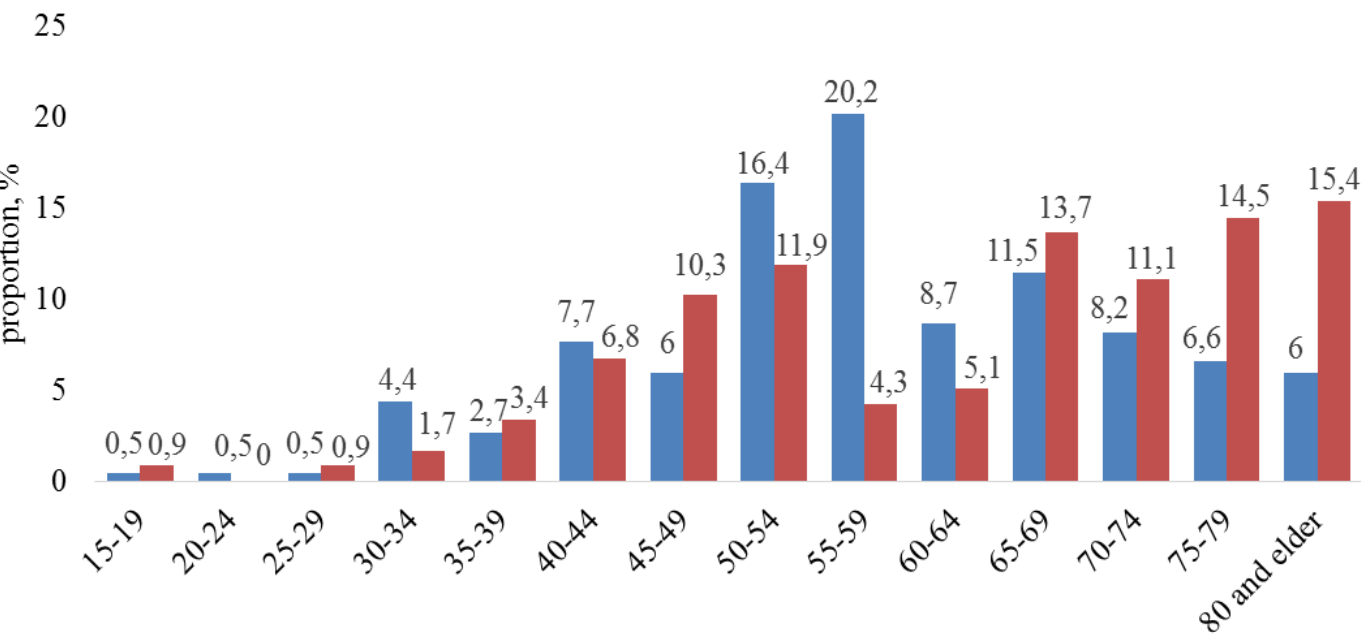

Age, years

men women

Fig. 2: The frequency of ACVA standardized by age and gender. 


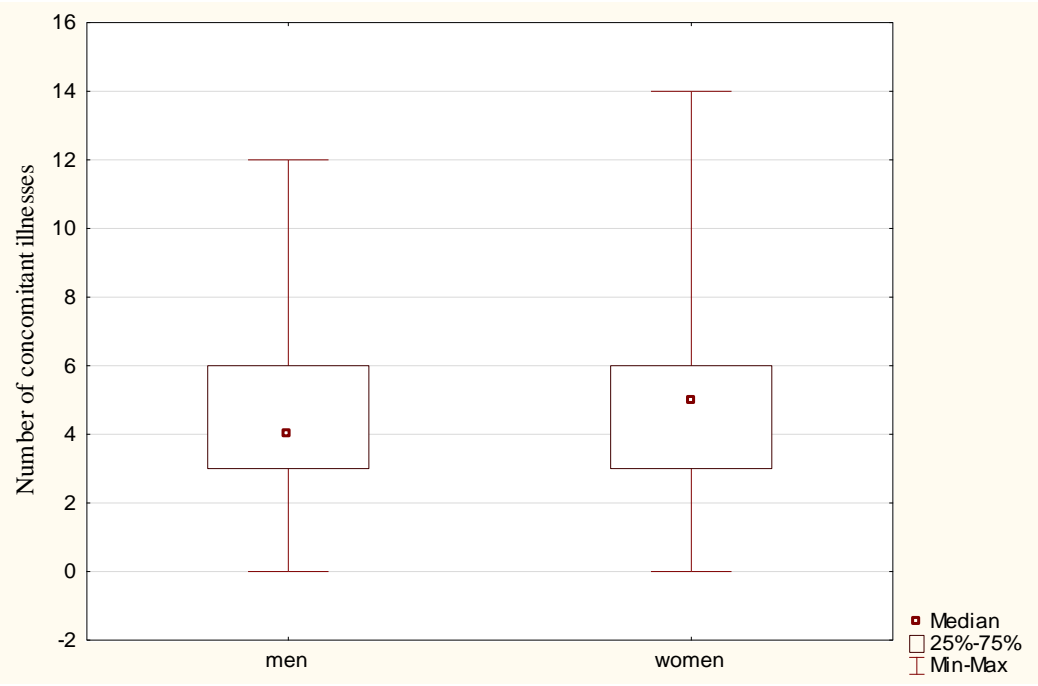

Fig.3. "Box-and-whisker" plot for comorbidities

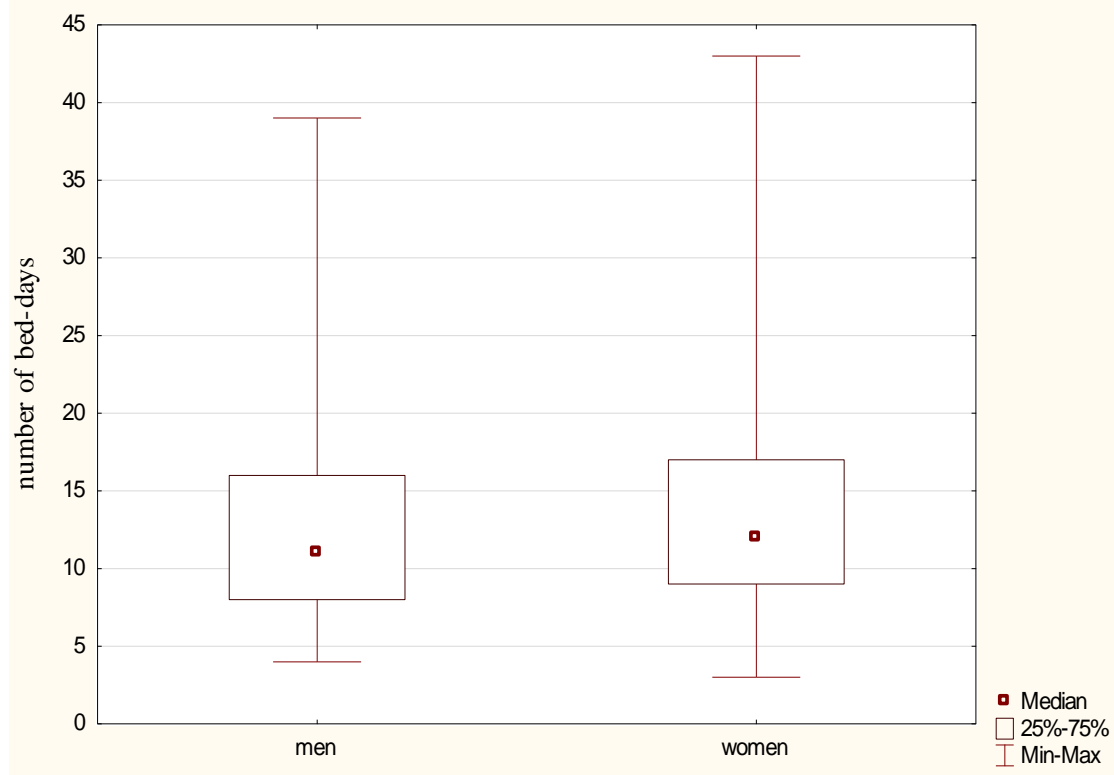

Fig.4. "Box-and-whisker" plot for spent bed-days

For female patients min amount of comorbidities also equaled 1, max -14 , the average amount of comorbidities was $4.5 \pm 2.28$ (median score of 5 disorders, $25 \%-3$ disorders, $75 \%-6$ disorders) ( $\mathrm{p}>0.10)$, so the research groups of patients did not differ significantly by the number of comorbidities. In the structure of concomitant diseases in patients with ACVA, the leading position belonged to hypertension with the frequency of $82.0 \%$ of cases. Bilateral hypertensive retinopathy was diagnosed in $59.7 \%$ of patients, heart failure at different stages - in $57.7 \%$, and ischemic heart disease - in $51.3 \%$ of patients. For male patients the min duration of hospitalization equaled 4 bed-days, max - 39 bed-days, average duration of hospitalization was $12.7 \pm 6.59$ beddays (median score of 11 bed-days, $25 \%$ - 8 bed-days, $75 \%-16$ bed-days) (fig.4). For females, min duration of hospitalization equaled 3 bed-days, max -43 bed-days, average duration of hospitalization was $13.9 \pm 7.55$ bed-days (median score of 12 beddays, $25 \%-9$ bed-days, $75 \%$ - 17 bed-days) ( $p>0.10)$, i.e. there was no statistically significant difference between the studied groups.

Content analysis of the IPPs helped to identify 198 drugs according to the INN or AN among 75 subgroups of the third level of ATC classification system. The drugs represented 10 organ-orsystem groups of the classification. They were prescribed to the patients for treatment of the main disorder as well as for comorbidities. Among the main organ or system groups of drugs that were used for treatment of ACVA, the max specific weight belonged to the Cardiovascular system group of drugs used for treatment of ACVA (C group) - 29.8\%. The specific weight of the $\mathrm{N}$ group (Nervous system group), A group (Alimentary tract and metabolism), and B group (Blood and blood forming organs) was 
$22.2 \%, 18.2 \%$ and $12.1 \%$ accordingly. Therefore, almost $83 \%$ of drug prescriptions were represented by the four organ or system groups $-\mathrm{C}, \mathrm{N}, \mathrm{A}$ and $\mathrm{B}$.

Prescriptions monitoring in terms of the groups of the third (therapeutic) level (table 1) showed that the max specific weight accounted for B01A group - Antithrombotic agents (6.6\%).

The results of frequency analysis (Levytska et al., 2014) proved the significance of 8 drugs from the statistical set. Particularly, they were Magnesium sulfas $8.1 \%$, L-lysine aescinat $-7.9 \%$, Potassium chloride $-6.2 \%$, Ipidacrine $-4.1 \%$, Enoxaparin $-3.9 \%$, Cerebrolysin - 3.6\%, Atorvastatin - 3.3\%, Choline alfoscerate $-2.7 \%$. These same medications were prescribed to $22.0 \%-66.7 \%$ of patients. For other drugs, the fraction of prescriptions was less than $2 \%$.

ABC-analysis (Levytska et al., 2014) showed that 40 drugs (or $20.2 \%$ of drug nomenclature) belong to group A, and had been prescribed to patients in $73.9 \%$ of cases. Drugs from group B, i.e. 55 names of medications (27.8\% of drug nomenclature), had been prescribed in $18.3 \%$ of cases. Finally, 103 drugs $(52.0 \%$ of nomenclature) had been prescribed only in $7.8 \%$ of cases.

The further stage of the research was drug consumption analysis on the behalf of ATC/DDD and DU 90\% methods (Levytska et al., 2014). We calculated the DDD for 141 drug (or $71.2 \%$ ) of the total count. However, it was not calculated for 6 of 8 mentioned above drugs that possessed high rates of prescriptions (Magnesium sulfas, L-lysine aescinat, Potassium chloride, Ipidacrine, Cerebrolysin, and Choline alfoscerate). It predetermined some underestimation of drug consumption. We discovered that the high rates of consumption were typical for 3 drugs as follows: Atorvastatin (1588 DDDs), Dexamethasone (1386.7 DDDs), and Enoxaparin (1381 DDDs). The significant rates of consumption were also typical for 6 following drugs: Rosuvastatin (685.5 DDDs), Vitaxon (600 DDDs), Acetylsalicylic acid (489 DDDs), Ramipril (452 DDDs), Neurorubine (450 DDDs), and Betahistine (417.3 DDDs). If we take into consideration that mentioned above Vitaxon and Neurorubine, as well as Neuromax and Milgamma (the DDDs of which were 182 and 176 respectively), are the fixed combination preparations of vitamins $\mathrm{B}_{1}, \mathrm{~B}_{6}$, and $\mathrm{B}_{12}$, it turns obvious that vitamin preparations altogether were characterized by considerably high rate of consumed DDDs - 1408 (see next). For 19 drugs the number of DDDs was between 110 (Cormagnesin) and 394 (Cardiomagnyl). The rates of consumption of the other analyzed drugs were of less than 100 DDDs.

The DU $90 \%$ analysis showed that $90 \%$ of consumed DDDs accounted for 45 drugs. Herewith, for 36 of them an interrelation between the number of consumed DDDs and the share of prescriptions was typical (Atorvastatin, Dexamethasone, Enoxaparin, Rosuvastatin, Vitaxon, Acetylsalicylic acid, Ramipril etc.). However, the drugs like Perindopril arginine, Lisinopril, Amlodipine etc., which belong to group of $90 \%$ of consumption, are characterized by the small share of prescriptions $(0.12-$ $0.28 \%$ ). Moreover, vice versa, drugs like Nicotinic acid, Warfarin, Quetiapine, Metamizole sodium etc. (which had the share of prescriptions ranging from 0.33 to $1.06 \%$ ), were not included into group of $90 \%$ of consumption.

For the drugs under research, the consumption indicator showing a number of DDDs per 100 bed-days was set. The calculations were performed using the formula as follows: DDDs/100 bed-days $=($ DDDs $x 100) /$ total number of bed-days $(n=3942)$. The drugs like Atorvastatin, Dexamethasone, and Enoxaparin were characterized by high numbers of DDDs per 100 bed-days (40.3, 35.2, and 35.0 accordingly). For Rosuvastatin, Vitaxon, Acetylsalicylic acid, Ramipril, Neurorubine, Betahistine and Cardiomagnyl the DDDs/100 bed-days indicators have the following rates: 17.4, 15.2, 12.4, 11.5, 11.4, 10.6 and 10.0 accordingly. For 46 drugs, the DDDs/100 bed-days indicator ranged from 1.0 to 9.0 , for the rest drugs this indicator's value was less than 1.0 .

Table 1: The share of separate therapeutic subgroups, prescribed for treatment of ACVA

\begin{tabular}{|c|c|c|c|c|}
\hline \multirow{2}{*}{\multicolumn{2}{|c|}{ Name of the therapeutic subgroup }} & \multirow{3}{*}{\begin{tabular}{|c|}
$\begin{array}{c}\text { ATC } \\
\text { code }\end{array}$ \\
B01A
\end{tabular}} & \multicolumn{2}{|c|}{ Amount of drugs by INN or AN } \\
\hline & & & Abs. & $\% *$ \\
\hline 1. & Antithrombotic agents & & 13 & 6.6 \\
\hline 2. & Psychostimulants, agents used for Attention deficit hyperactivity disorder (ADHD) and nootropics & N06B & 12 & 6.1 \\
\hline 3. & Angiotensin-converting enzyme (ACE) inhibitors, combinations & C09B & 8 & 4.0 \\
\hline 4. & Other cardiac preparations & $\mathrm{C} 01 \mathrm{E}$ & 7 & 3.5 \\
\hline 5. & Anti-inflammatory and antirheumatic products & M01A & 6 & 3.0 \\
\hline 6. & Vitamin B1, plain and in combination with vitamin B6 and B12 & A11D & 6 & 3.0 \\
\hline 7. & Beta blocking agents & $\mathrm{C} 07 \mathrm{~A}$ & 5 & 2.5 \\
\hline 8. & ACE inhibitors & $\mathrm{C} 09 \mathrm{~A}$ & 5 & 2.5 \\
\hline 9. & Antipsychotics & N05A & 5 & 2.5 \\
\hline & Antidepressants & N06A & 5 & 2.5 \\
\hline & Intravenous solution additives & B05X & 5 & 2.5 \\
\hline \multirow{2}{*}{\multicolumn{2}{|c|}{ Total: }} & & 77 & 38.7 \\
\hline & & & 121 & 61.3 \\
\hline
\end{tabular}

* - share of the total amount of drugs $(\mathrm{n}=198)$ 
Table 2: Distribution of Atorvastatin prescriptions by the trade names for ACVA patients.

\section{Trade name of the drug, manufacturer}

\begin{tabular}{|c|c|c|c|}
\hline & tab. & mg & DDDs \\
\hline Atoris, tab. $10 \mathrm{mg} \mathrm{N}$ 30, KRKA, Slovenia & 46 & 460 & 23 \\
\hline Atoris, tab. $20 \mathrm{mg} \mathrm{N}$ 30, KRKA, Slovenia & 348 & 6960 & 348 \\
\hline Atoris, tab. $30 \mathrm{mg} \mathrm{N}$ 30, KRKA, Slovenia & 23 & 690 & 34.5 \\
\hline Atoris, tab. $40 \mathrm{mg} \mathrm{N} 30$, KRKA, Slovenia & 64 & 2560 & 128 \\
\hline Atoris, tab. $60 \mathrm{mg} \mathrm{N} \mathrm{30,} \mathrm{KRKA,} \mathrm{Slovenia}$ & 73 & 4380 & 219 \\
\hline Total Atoris & & & 752.5 \\
\hline Atorvastatin, tab. $10 \mathrm{mg} \mathrm{N} \mathrm{30,} \mathrm{Pfizer,} \mathrm{USA}$ & 43 & 430 & 21.5 \\
\hline Atorvastatin, tab. $20 \mathrm{mg} \mathrm{N} 30$, Pfizer, USA & 46 & 920 & 46 \\
\hline Total Atorvastatin & & & 67.5 \\
\hline Atorvastatin-Teva, tab. $40 \mathrm{mg} \mathrm{N} 30$, Teva, Israel & 27 & 1080 & 54 \\
\hline Atorvastatin-Teva, tab. $80 \mathrm{mg} \mathrm{N} \mathrm{30,} \mathrm{Teva,} \mathrm{Israel}$ & 42 & 3360 & 168 \\
\hline Total Atorvastatin-Teva & & & 222 \\
\hline Tolevas, tab. e/c 20 mg N 30, Nobel, Turkey & 49 & 980 & 49 \\
\hline Tolevas, tab. e/c $40 \mathrm{mg} \mathrm{N} 30$, Nobel, Turkey & 28 & 1120 & 56 \\
\hline Total Tolevas & & & 105 \\
\hline Tulip, tab. e/c 20 mg N 30, Lek, Slovenia & 16 & 320 & 16 \\
\hline Total Tulip & & & 16 \\
\hline Livostor, tab. e/c 10 mg N 30, Kyiv Vitamin Factory, Ukraine & 27 & 270 & 13.5 \\
\hline Livostor, tab. e/c 20 mg N 30, Kyiv Vitamin Factory, Ukraine & 72 & 1440 & 72 \\
\hline Livostor, tab. e/c $40 \mathrm{mg}$ N 30, Kyiv Vitamin Factory, Ukraine & 63 & 2520 & 126 \\
\hline Total Livostor & & & 211,5 \\
\hline Lipodemin, tab. $10 \mathrm{mg} \mathrm{N}$ 30, Propharma International, Malta & 24 & 240 & 12 \\
\hline Lipodemin, tab. $20 \mathrm{mg} \mathrm{N} \mathrm{30,} \mathrm{Propharma} \mathrm{International,} \mathrm{Malta}$ & 11 & 220 & 11 \\
\hline Total Lipodemin & & & 23 \\
\hline Liprimar, tab. e/c 20 mg N 30, Pfizer, USA & 8 & 160 & 8 \\
\hline Liprimar, tab. e/c $40 \mathrm{mg} \mathrm{N} 30$, Pfizer, USA & 30 & 1200 & 60 \\
\hline Liprimar, tab. e/c $80 \mathrm{mg} \mathrm{N} 30$, Pfizer, USA & 20 & 1600 & 80 \\
\hline Total Liprimar & & & 148 \\
\hline Storvas, tab. e/c $10 \mathrm{mg} \mathrm{N} 30$, Ranbaxy, India & 21 & 210 & 10.5 \\
\hline Storvas, tab. e/c 20 mg N 30, Ranbaxy, India & 12 & 240 & 12 \\
\hline Total Storvas & & & 22,5 \\
\hline Amvastan, tab. e/c $20 \mathrm{mg}$, Rottapharm, Germany & 20 & 400 & 20 \\
\hline Total Amvastan & & & 20 \\
\hline Total: & & & 1588 \\
\hline
\end{tabular}

The results of drugs consumption analysis for selected trade names are represented by the example of Atorvastatin that is characterized by max number of consumed DDDs (Table 2). The DDD for this drug is $20 \mathrm{mg}$ if taken per os (WHO, 2016). Max drug consumption was typical for different dosage of Atoris, KRKA (Slovenia), i.e. 752.5 DDDs. Taking into consideration current approaches to treatment of ACVA, we analyzed drug consumption in the aspect of common groups of preparations that are used for basic and specific therapy, and for secondary prevention of the disorder. These are antihypertensive drugs, anticoagulants, antiplatelet agents, and statins. In general, antihypertensive agents were prescribed to $62 \%$ of patients, statins - to $38 \%$, anticoagulants - in $43 \%$ of cases, and antiplatelet agents - to $46.3 \%$ of patients (table 3 ).

Table 3: Results of the consumption analysis for separate groups of drugs.

\begin{tabular}{cccc}
\hline Name of the group & $\begin{array}{c}\text { Share of patients who } \\
\text { were prescribed the } \\
\text { drugs, \% }\end{array}$ & $\begin{array}{c}\text { Total } \\
\text { number } \\
\text { of DDDs }\end{array}$ & $\begin{array}{c}\text { DDDs/100 } \\
\text { bed-days }\end{array}$ \\
\hline Antihypertensive drugs & 62.0 & 3261.7 & 82.7 \\
Statins & 38.0 & 2312.2 & 58.7 \\
Anticoagulants & 43.0 & 1520.4 & 38.6 \\
Antiplatelet drugs & 46.3 & 1301.0 & 33.0 \\
\hline
\end{tabular}

Consumption of the mentioned groups of drugs was $58 \%$ of DDDs. According to the valid in Ukraine medical-and- technological documents that regulate the provision of medical care to patients with ACAV (Ministry of Health of Ukraine, 2012), there are several separate indicators of medical care quality. This, in particular, is prescribing of Acetylsalicylic acid (antiplatelet agent) within 48 hours of the onset of stroke symptoms, prescribing of antithrombotic agents (antiplatelet drugs or anticoagulants) and lipid-lowering pharmacotherapy (statins) at the time of discharge from the hospital (Ministry of Health of Ukraine, 2012). Considering this, we believe, optimization of prescribing the mentioned groups of drugs for such patients is advisable. As for the vitamin B group, analyses like frequency of prescribing, number of consumed DDDs, and DDDs/100 bed-days show that in the investigated inpatient hospital these drugs were prescribed rather often (particularly, fixed combinations of vitamin B complex containing Thiamine chloride (B1), Pyridoxine hydrochloride (B6) and Cyanocobalamin (B12)) (table 4). Besides, a considerable number of consumed DDDs belong to them.

It is well known that group B vitamins decrease levels of homocysteine - one of the risk factors for cardiovascular disorders. The question of their use or non-use for patients with ACVA remains open and controversial because the results of many researches do not give a clear answer about their benefits, harm or futility in treatment of ACVA (Meng et al., 2010; Yan Ji et al., 2013). However, in the native Ukrainian adopted evidence- 
based clinical guidelines "Recommendations on managing patients with ischemic stroke and transient ischemic attack" it is mentioned that homocysteine-lowering vitamins (Folic acid, Pyridoxine hydrochloride and Cyanocobalamin) do not decrease risk of recurrent stroke and can increase frequency of vascular events; although at present time further studies proceed (Ministry of Health of Ukraine, 2012). That is why we consider investigation of prescribing vitamin preparations to patients with ACVA a curious topic for further research.

Table 4: Results of vitamin B consumption analysis.

\begin{tabular}{lccc} 
Name of the drug & $\begin{array}{c}\text { Share of } \\
\text { patients who } \\
\text { were prescribed } \\
\text { the drugs, \% }\end{array}$ & $\begin{array}{c}\text { Total } \\
\text { number } \\
\text { of } \\
\text { DDDs }\end{array}$ & $\begin{array}{c}\text { DDDs/ } \\
\mathbf{1 0 0} \\
\text { bed- } \\
\text { days }\end{array}$ \\
\hline $\begin{array}{l}\text { Fixed combination of vitamins } \mathrm{B}_{1}, \\
\mathrm{~B}_{6} \text { and/or } \mathrm{B}_{12}\end{array}$ & 30.0 & 1408 & 35.7 \\
\hline Thiamine chloride $\left(\mathrm{B}_{1}\right)$ & 5.7 & 121 & 3.1 \\
\hline Pyridoxine hydrochloride $\left(\mathrm{B}_{6}\right)$ & 2.3 & 13.1 & 0.3 \\
\hline
\end{tabular}

\section{CONCLUSIONS}

1 The results of our study prove the tendency to occurrence of ACVA in patients aged 50 and over with the vast prevalence of cerebral infarction over hemorrhage. The disorder is interlinked with one or few comorbidities, especially hypertension. Therefore, we believe, increasing awareness of ACVA and problems of its medical treatment (including pharmaco-economical aspect) among specialists and risk-groups of patients is an important issue directed on the disease prevention, especially in Ukraine. This might be provided by means of specially designed workshops and distribution of important information on social media and networks.

2 As far as we found a number of consumption problems and cases of inappropriate drug prescribing, the results of our research should act as a background for prescribing rational pharmacotherapy to patients with ACVA, optimization of both pharmacotherapy in some particular cases, and the process of its quality regulation. We believe, the data developed in this research should be taken into consideration by the current health care system of Ukraine and included into State programs on quality of pharmacotherapy improvement.

\section{Financial support and sponsorship: Nil.}

Conflict of Interests: There are no conflicts of interest.

\section{REFERENCES}

ATC/DDD Index 2016, 2016. Available at: https://www.whocc.no/atc_ddd_index/[Accessed 15 Aug 2016].

Basavaraju ThJ, Panchaksharimath P. A retrospective study on drug utilization in patients with acute exacerbation of bronchial asthma in adults at a tertiary teaching hospital in Bengaluru. Egyptian Journal of Chest Diseases and Tuberculosis, 2016; 1(65):19-22 Available at: http://www.sciencedirect.com/science/article/pii/S042276381530090X [Accessed 20 March 2016]

Filipets OO, Pashkovsky VM. Stroke burden in Ukraine: analysis of the official stroke statistics and overview of population-based epidemiological studies. Clinical and experimental pathology (ukr), 2014; 13(3):189-193

Hanssens Y, Deleu D, Balushi KAl et al. Drug utilization pattern of anti-epileptic drugs: a pharmacoepidemiologic study in Oman. J. Clin. Pharm. Ther., 2002; 27(5):357-364

International Statistical Classification of Diseases and Related Health Problems 10th Revision (version 2015), 2015 Available at: http://apps.who.int/classifications/icd10/browse/2015/en\#/ [Accessed 16 Dec 2015]

Kotvitska AA., Lobova IO. Of consumption neuroprotective drugs for the treatment of ischemic stroke in Ukraine. Management, Economics and Quality Provision in Pharmacy (ukr), 2013; 5(31):49-58.

Levytska OR, Hromovyk BP. 2014. Ischemic stroke: clinicaland-pharmaceutical aspects. Lviv, Ukraine: Liga-press Ltd.

Levytska OR, Hromovyk BP. Pharmacoepidemiological aspects of acute cerebral vascular pathology. Clinical Pharmacy, Pharmacotherapy and Medical Standardization (ukr), 2012; 4:175-179.

Meng L, Hong K-S, Chang Sh-Ch, Saver JL. Efficacy of Homocysteine-Lowering Therapy with Folic Acid in Stroke Prevention: A Meta-Analysis. Stroke, 2010; 41:1205-1212. Available at: http://stroke.ahajournals.org/content/41/6/1205.full [Accessed 16 March 2016]

Ministry of Health of Ukraine order No. 602 from 3 Aug 2012 "On approval and introduction of medical-and-technological documents for standardization of care in ischemic stroke", 2012. Available at: http://www.moz.gov.ua/ua/portal/dn_20120803_602.html [Accessed 1016 Dec 2015]

Ministry of Health of Ukraine order No. 651 from 26 Apr 2013 "On principals of appropriate pharmacotherapeutic practice and polypragmasy prevention", 2013. Available at: http://www.apteka.ua/article/249799 [Accessed 10 Dec 2015]

Mishchenko OYa, Adonkina VYu. Pharmacoepidemiological studies of consumption of antihypertensive drugs that affect the reninangiotensin system. Management, Economics and Quality Orovision in Pharmacy (ukr), 2011; 5(19):58-63.

Revenko IL. Epidemiology of stroke in Ukraine. Zaporizhia Medical Journal (ukr), 2010; 3(12):42-47 Available at: http://nbuv.gov.ua/UJRN/Zmzh_2010_12_3_14 [Accessed 14 Dec 2015]

Sagar SB, Nilima AK. Systematic review of drug utilization studies \& the use of the drug classification system in the WHO-SEARO Region. Indian J Med Res, 2015; 142:120-129 Available at: http://www.icmr.nic.in/ijmr/2015/august/7.pdf [Accessed 12 April 2016]

Serhiienko VI, Bondareva IB, 2000. Mathematical statistics in clinical trials (rus). Moscow, Russia: "GEOTAR-Media" Publishing Group

Sharonjeet K, Sujit R, Navjot K [et al.]. Drug Utilization Study in Medical Emergency Unit of a Tertiary Care Hospital in North India. Emergency Medicine International, 2014; Available at: http://dx.doi.org/10.1155/2014/973578 [Accessed 20 March 2016]

Smuseva ON, Shatalova OV, Solovkina YuV. Analysis of drug consumption in angina treatment. Siberian Medical Journal, 2012; 4(27):79-82 Available at: http://cyberleninka.ru/article/n/analizpotrebleniya-lekarstvennyh-sredstv-pri-lechenii-stenokardii [Accessed 12 Dec 2015]

Volodina A, Bertsche Th, Kostev K [et al.]. Drug utilization patterns and reported health status in ethnic German migrants (Aussiedler) in Germany: a cross-sectional study. BMC Public Health, 2011; 11:509 Available

at: http://bmcpublichealth.biomedcentral.com/articles/10.1186/1471-2458-11509 [Accessed 20 March 2016]

WHO International Working Group for Drug, Statistics Methodology, WHO Collaborating Centre for Drug Statistics Methodology, WHO Collaborating Centre for Drug Utilization Research and Clinical Pharmacological Services. Introduction to drug utilization research WHO, 2003.2 Available at: http://apps.who.int/medicinedocs/pdf/s4876e/s4876e.pdf [Accessed 15 Aug 2015] 
World Health Statistics 2014. 2014. Available at: http://www.who.int/mediacentre/news/releases/2014/world-healthstatistics-2014/en/ [Accessed 12 Dec 2015].

Yakovleva LV, Ribka AV. The practice of consumption nootropic drugs. Clinical Pharmacy, Pharmacotherapy and Medical Standardization (ukr), 2013; 2:159-166

Yan Ji, Song Tan, Yuming $\mathrm{Xu} \quad\left[\begin{array}{ll}e t & a l .\end{array}\right]$. Vitamin B supplementation, homocysteine levels, and the risk of cerebrovascular disease: A Meta-Analysis. Neurology, 2013; 81(15):1298-1307 Available at: http://www.neurology.org/content/81/15/1298 [Accessed 20 March 2016]

\section{How to cite this article:}

Levytska OR, Hromovyk BP, Unhurian LM, Kostyana KV. Clinical-epidemiological and pharmacoepidemiological investigation of acute cerebrovascular accidents. J App Pharm Sci, 2017; 7 (07): 168-175. 